\title{
Discussion on annual report about reservoir dam safety
}

\author{
aLijia Ma, bShichen Zhang, 'Dawei Zhang \\ a,bGuangdong Technical College of Water Resources and Electric Engineering, Guangdong, China \\ 'Nanjing Hydraulic Research Institute, Jiangsu, China
}

KEYWORD: reservoir dam, safety management, annual report

ABSTRACT: In order to consolidate the achievements of hydraulic engineering system reform and rehabilitation of defected reservoir, and to further promote the development of dam safety management, annual report about reservoir dam safety is proposed. This paper analyzes the function and significance of annual report, and puts forward suggestions on the content and system construction of reservoir dam safety annual report.

\section{INTRODUCTION}

Reservoir dam management is divided into two classes, asset management and safety management. Safety management is the basis of asset management. Around the reservoir dam safety, our country has established management responsibility system of dam safety, registration system of dam, dam safety assessment system, demotion and retirement system of reservoir and so on. Hydraulic engineering system reform and rehabilitation of defected reservoir, has changed over ill-conditioned reservoirs and undeveloped management, and serve as a guarantee for basic safety operation of the dam. To consolidate the achievements of the preliminary work and further improve the level of reservoir dam safety management, annual reporting system about reservoir dam safety could be established through summing up the practical experience and learning from international experience.

\section{THE FUNCTION AND SIGNIFICANCE OF ANNUAL REPORT}

The first is to answer the demands of interests on the reservoir dam safety.

As to the public safety, in order to safeguard people's life safety and property safety, protect the dam from breaking, overtopping and destruction, the people downstream want to know whether the reservoir dam is safe. As to production safety, reservoir employers need to know safety situation of the reservoir dam. As to safety responsibility system, every liability subject must master and control the reservoir dam safety. Especially, government departments should not only protect public safety but also supervise production safety.

Existing dam safety assessment can answer the question whether the dam is safe, but the time period is 5 years or 6 10 years which span is too large to meet the increasing safety needs of people.

The second is to urge the reservoir management unit to do the safety management work well. In our country, careless inspection, calibration not in time, unreliable monitoring data, analysis and edit unsystemly, results of analysis not put into use and so on are universal in dam safety management. On the one hand, establishing the annual reporting system of reservoir dam safety can urge water conservancy unit to do daily safety management work well, analyze patrol inspection results and observation data of dam timely and report the state of dam safety. On the other hand it can instruct reservoir management unit to do work plans of next year and strengthen inspection and management of key parts and key projects.

\section{The third is to provide management means for the government department of water administration.}

In our country, dam safety submission of information system is as follows: reporting and backing up analysis reports in form of on-site inspection or data analysis in every 5 or 6-10 years to superior departments other relevant units normally. Or when the dam encounters prominent problems and sudden danger, it should report it to the relevant units according to regulations. The submission of information system prefer to report emergency and safety appraisal results, with the characteristics 
of emergency (such as the information of emergency) or long time interval (such as secure identification information). As to results of daily safety inspection and patrol inspection, it will not be reported to the superior departments which form into a habit that just report when in danger, not report when safe. This habit is bad to safety monitoring of dam. On the one hand, supervision units cannot grasp the situation of dam safety and publish authoritative information timely. On the other hand, supervision units are hard to focus the point to allocate resources efficiently so as to improve supervision effect.

The last is to provide a basis for the assessment of hydraulic engineering management. After approving, the conclusion and suggestion of the annual report should be an important basis for the work plan and budget of the maintenance and operational management next year.

\section{CONTENTS OF ANNUAL REPORT ABOUT RESERVOIR DAM SAFETY}

Based on the internationally and domestically relative experience, combing current situation and needs of reservoir dam safety management in our country, the annual report of dam safety should include safety inspection and monitoring, operation, maintenance, defect treatment and safety situation of this year. Meanwhile, put forward the next year's safety management work plans and proposals. Specific content as follows:

(1) Overview of reservoir project and summary of engineering operation

Here is the basic situation of reservoir project: describing the operation of this year, such as coming water, discharge frequency, discharge volume, operation status of the structure, including waterretaining structure, flood releasing structure, energy dissipation structure, near dam bank slope and so on.

(2) On-site safety check

Dam safety inspection includes letting operation management unit do daily inspection and flood control and drought relief headquarters and reservoir competent department with operation management unit together comb and summarize special inspection conditions of pre-flood, after-flood and possible period and judge safety behavior of dam synthetically.

(3) Perambulation inspection and safety monitoring

Describe the abnormal phenomenon and the location, characteristics and operating conditions during perambulation and inspection and make a preliminary judgment. Put forward suggestions on the key parts of the inspection in future.

Describe operation and maintenance condition of this year. On the basis of arranging and editing the monitoring data, we should extend the time of monitoring data this year and analysis of hydrograph and correlation line. According to the observation data, we will make a preliminary judgment on safety behavior of the project, and focus on the key parts and project of the monitoring in the future.

(4) Operation

According to the reply of State Flood Control and Drought Relief Headquarters, evaluate flood control operation and optimal operation, what's more, analyze all-round operation when circumstances permit. As to reasons, results and handing information by not following operation rules, it can reference Guidelines for the Compilation of Reservoir Operation Procedures (for Trial Implementation) released in 2012.

(5) Engineering maintenance

Check information of implementing the plan about engineering maintenance in the beginning of the year or the end of last year. Illustrate the problem or the left problem during maintenance, especially the problem which could influence the safety of the dam during flood season or after flood season. According to the above, evaluate the engineering maintenance and put forward emphasis of maintenance and suggestions of implement plan of the next year.

(6) Emergency management

As to emergency of this year (floods, earthquakes, engineering danger, etc.), whether implement the original contingency plan? If not, what is the actual implementation? How to revise the plan? Ac- 
cording to the actual process and consequences of the emergency, put forward the corresponding experiences and lessons and give suggestions how to further improve the emergency plan in the future.

(7) Conclusions and recommendations

Based on the summary and analysis of all aspects above, make judgments on the reservoir dam safety, and put forward suggestions on maintenance and how to protect the dam safety better and improve the management level.

\section{DISCUSSION OF BUILDING RESERVOIR DAM SAFETY ANNUAL REPORTING SYSTEM}

\section{scope of application}

(1) Small scheme: the scope of application to maintain the original provisions, the scope of reference to maintain the original provisions. That is applicable to dams of more than $15 \mathrm{~m}$ high or capacity of more than 1 million $\mathrm{m}^{3}$ reservoir dam, dam height is less than $15 \mathrm{~m}$ or capacity between $0.1 \sim 1$ million $\mathrm{m}^{3}$ small reservoir dam in the light of the implementation.

(2) Medium scheme: scope of application maintained the original provisions, the reference range of small reservoirs can take a relatively simplified (content can be according to the reservoir conditions simplified, at the implementation level also does not require mandatory).

(3) Large scheme: considering the social progress, the dam safety requirements continue to increase, the scope of application will be extended to all nearly 100 thousand reservoirs.

\section{The subject of compilation}

As to large and medium-sized reservoirs and some small reservoirs in good condition, technical leaders inside of reservoir operation and management unit are responsible for compilation.

The liability subject of small reservoirs is complex. According to the Small Reservoir Management Regulations, the competent department's duty of small reservoirs belonging to rural collective economic organization should be in charge of township (town) people's governments. When the township (town) people's governments (sub-district office) don't have the professional technical capacity, it can be entrusted to capable unit.

\section{The way of compilation}

In general, reservoir management unit or the owner shall submit reservoir dam safety report to the competent department annually, and accept investigation and judgment of reservoir dam competent department or its client. The reservoir dam competent department should report general safety situation of the dam to superior competent department or administrative department of the same grade.

\section{Submission deadline}

Submit the dam safety report of one year during the pre-flood next year and suggested submission deadline is March. On the one hand, there's buffer time for engineering safety management guidance during pre-flood period. On the other hand, it's convenient to facilitate this year's capital arrangements.

\section{Investigation and judgment}

The dam safety annual report can be invested and judged by experts engaging in dam safety management of administrative competent. In principle, carry it out according to reservoir classification management and need to be adjusted according to the situation.

\section{Application of the report}

The judged dam safety annual report is the important basis of safety supervision, management and safety appraisal. The conclusion and suggestion should be the important basis of engineering maintenance, operation management and budgetary resources. The implementation should be the important test content of compilation unit position.

\section{The record of the report}

After judgment of the dam safety annual report, the compilation unit should submit the final report, investigation and suggestion to judgment department with the duration of one month. 


\section{Funding}

The reservoir competent department or management department is responsible for raising the cost of the compiling and judging dam safety annual report which spend from the local government budget for engineering maintenance and operation management each year.

\section{Organization implementation path}

In order to successfully carry out the dam safety annual report system, the following work must be strictly completed:

(1) Strict implementation of the regular safety inspection and safety assessment system of reservoir dam.

(2) Strict implementation of dam safety monitoring and monitoring data analysis system.

(3) Scientific formulation and strict implementation of the reservoir operation rules.

(4) Strict implementation of the dam safety management emergency plan system.

(5) Sort out the information to carry out the preparation of the annual report, report, review, record.

\section{CONCLUSION}

With the development of economy-society, the demand of safety has become increasingly urged which need further improve the level of safety management. In the existing reservoir dam safety management system, construction of dam safety annual reporting system is an inevitable choice of improving the level of safety management and a key measure for improvement of reservoir dam safety supervision system.

\section{ACKNOWLEDGEMENTS}

This work was financially supported by the Special Fund for Public Welfare Industry of Ministry of Water Resources of China.

\section{REFERENCES:}

[1] The Reservoir Dam safety Management Regulation. No. 77 of the State Council of the people's Republic of China, 1991.3;

[2] Rogério de ABREU MENESCAL. Dam safety Management Regulations in the World, 2009.12;

[3] Zhenghua Yang. "Analysis of Current Situation and Standard Regulations of Reservoir Dam safety Management in China". Dam safety management center of Ministry of water resources. 2010.8;

[4] Jinbao Sheng, Lei Li. “Adaptability Analysis of Worldwide Dam safety Policy OP4.37 to China”. Dam safety management center of Ministry of water resources. 2010.8;

[5] The Swiss Federal Council. Water Retaining Facilities Ordinance (WRFO), 2013;

[6] Lei Li. "The Research Report of the Reservoir Dam safety Management Regulation". Dam safety management center of Ministry of water resources. 2010.6;

[7] Hui Yuan. "The Analysis of the Reservoir Dam safety Management Regulation". Dam safety management center of Ministry of water resources.2010.6;

[8] Reservoir dam risk management and revision seminar summary report of 《Dam safety management regulations 》.Dam safety management center of Ministry of water resources.2010.6;

[9] "The Research Report of dam safety legal framework". the World Band.2002;

[10] "The safety management measures of small reservoir". Ministry of water resources.2010.5. 